\section{La France et l'OTAN : vers la normalisation ?}

\author{
Courrier hebdomadaire $n^{\circ} 2005$ - par A. Dumoulin - 47 p. - 2008 - 6,90€
}

En 1966, la France se retire du commandement intégré de l'OTAN. Son actuelle réintégration n'est pas une rupture ni le fruit d'une révolution, mais plutôt l'aboutissement d'un processus engagé par François Mitterrand et poursuivi par Jacques Chirac.

En fait, la politique française a toujours joué sur plusieurs plans, entre indépendance nationale, soutien à la défense européenne et engagements au sein de l'Alliance. L'autonomie européenne en matière de défense a toujours fait l'objet d'un soutien important de la part de Paris, avec des résultats qui ne furent pas toujours à la hauteur des ambitions.

Depuis la fin de la Guerre froide et le 11 septembre 2001, le paysage a changé. Les États-Unis ont compris que sans les Européens, ils n'ont pas beaucoup d'alliés sur qui compter pour disposer d'une armée crédible et qui s'engage sur le terrain. De son côté, Paris a pris des initiatives pragmatiques sur des dossiers opérationnels, techniques et militaires durant la présidence du Conseil de l'Union européenne au second semestre 2008, sortant ainsi des grands concepts idéologiques européistes.

8

Bon de commande à renvoyer par fax (02/219.79.34), par courrier (CRISP, Place Quetelet 1A - 1210 Bruxelles), ou par e-mail (info@ crisp.be)

Je soussigné : Nom : Prénom :

Organisation/Société :

Rue et $n^{\circ}$ :

Code postal : Commune :

Pays

Commande

.... exemplaire(s) de «La France et l'Otan : vers la normalisation ? », $C H \mathrm{n}^{\circ} 2005$ au prix de 6,90 euros

Une participation aux frais d'expédition sera facturée en sus.

Date Signature 
PLACE QUETELET, $1^{\mathrm{A}}$ • B-1210 BRUXELLES • http://www.crisp.be T. : 32 (0)2 2110180 • F. : 32 (0)2 2197934 • Comptes : 310-0271576-62 • 000-0714991-04

TABLE DES MATIERES

\section{INTRODUCTION}

1. LES 60 ANS DE L'OTAN : 1949-2009

1.1. Place de l'OTAN durant la guerre froide

1.2. L'OTAN apres la chute du mur

1.3. Scénarios d'avenir pour l'Organisation atlantique

2. ÉVOLUTION DE LA PLACE DE LA FRANCE DANS L'ALLIANCE ATLANTIQUE

2.1. La France et la défense de l'avant

2.2. Le retrait du commandement intégré

2.3. Le rapprochement de la France dans les années 1990

3. VERS LE RETOUR DANS L'ORGANISATION INTÉGRÉE EN 2009 ?

3.1. Le contexte géopolitique après le 11 septembre 2001

3.2. «L'otanisation » des structures et des moyens militaires français

3.3. La participation de la France aux missions de l'OTAN

3.4. La conditionnalité de l'intégration

4. LA FRANCE ET L'OTAN : ARGUMENTAIRES, HYPOTHÈSES ET SCÉNARIOS

4.1. Arguments en faveur de la réintégration complète

4.2. Arguments d'opposition

ANNEXES 